\title{
Formação de pesquisadores é prioridade da SBAFS
}

Pedro C Hallal ${ }^{1}$

Rodrigo S Reis ${ }^{2,3}$

Rev Bras Ativ Fis Saúde p. 1-1

DOI: http://dx.doi.org/10.12820/2317

1634.2013v18n1p1

1 Presidente da SBAFS

2 Vice-presidente da SBAFS

3 Representante da ISPAH para as Américas

A formação de recursos humanos para a condução de pesquisas de excelência é uma das prioridades da atual diretoria da Sociedade Brasileira de Atividade Física e Saúde (SBAFS). Em função disso, a SBAFS está organizando, em parceria com o Centro de Controle e Prevenção de Doenças (CDC) dos Estados Unidos, a Sociedade Internacional de Atividade Física e Saúde (ISPAH) e universidades Brasileiras (UFPEL, PUCPR e UFPR), o I Curso Internacional de Atividade Física e Saúde Pública.

O evento será realizado na cidade de Curitiba,PR, entre os dias 07 e 13 de Julho de 2013. O funcionamento do evento é bastante peculiar, e segue o formato do tradicional curso de atividade física e saúde pública organizado há mais de 15 anos pelo Centro de Prevenção e Pesquisa da Universidade da Carolina do Sul, EUA (http://www.sph.sc.edu/paph/about.htm). Seguindo o modelo original iniciado nos EUA, o curso reúne em grupo seleto de alunos (20 alunos, no caso do curso nacional), em estado de imersão, por um período de uma semana. Nesse período, os alunos convivem diariamente com os professores do curso, por meio de palestras, sessões de orientação individual, elaboração de projetos de pesquisa, atividades de confraternização, entre outras.

Este modelo de curso está sendo adotado pela ISPAH e o Brasil foi escolhido para sediar o primeiro curso desta natureza. A escolha não foi ao acaso, a existência de uma Sociedade e uma Revista organizadas em torno da temática da atividade física e saúde e o crescente destaque do Brasil no cenário internacional de pesquisa foram alguns dos fatores determinantes para a iniciativa.

$\mathrm{Na}$ primeira edição do curso no Brasil, teremos a presença dos professores James Sallis e Michal Pratt dos Estados Unidos e da professora Olga Lucia Sarmiento da Colômbia. Além deles, o evento contará com um corpo docente de pesquisadores brasileiros da área, além de representantes de órgãos de fomento e instituições governamentais. O corpo discente será formado por pesquisadores doutores ou doutorandos com perspectiva de continuidade na área de atividade física e saúde.

Somado ao já tradicional Congresso Brasileiro de Atividade Física e Saúde, esperamos que o Curso de Métodos Avançados de Pesquisa em Atividade Física e Saúde Pública se consolide como uma ação da SBAFS para a formação de recursos humanos preocupados e preparados para lidar com os defafios da promoção da atividade física no Brasil. Esperamos vocês em Curitiba. 